\title{
ENIGE BESCHOUWINGEN OVER DE CONTROLERENDE FUNCTIES VAN DE OVERHEIDSACCOUNTANT
}

\author{
door A. de Nijs
}

Bij de nadere uitwerking van zijn „Vertrouwenstheorie” zijn door Prof. Limperg de functies van de accountant als volgt onderscheiden:

a. controlerend (en adviserend) orgaan van de bedrijfsleiding;

b. controlerend (en adviserend) orgaan van het maatschappelijk verkeer.

Met betrekking tot de vervulling van deze functies bestaan de volgende mogelijkheden:

1. beide functies worden vervuld door dezelfde functionaris.

Deze situatie is de meest voorkomende; het zal echter duidelijk zijn, zo stelt Limperg, dat de eisen, welke aan de functie sub b. gesteld worden, uiteindelijk de taak en de verantwoordelijkheid van de accountant bepalen.

Het maatschappelijk verkeer verlangt van de accountant een deskundig en onafhankelijk oordeel omtrent de juistheid van de door de bedrijfsleiding afgelegde verantwoording.

De deskundigheid kan door studie en ervaring worden verkregen; de onafhankelijkheid kan slechts aanwezig zijn bij een buiten het bedrijf staande controleur (dus functioneel onafhankelijk, niet ondergeschikt aan de bedrijfsleiding).

Worden beide functies door dezelfde functionaris vervuld, dan kan dat dus niet anders geschieden dan door een buiten het bedrijf staande deskundige: de externe accountant.

2. de functies worden vervuld door verschillende functionarissen.

Voor de functie sub a. kan dan een functionaris in dienst van de onderneming worden aangetrokken; hij controleert uitsluitend ten behoeve van de bedrijfsleiding, hij is hieraan functioneel ondergeschikt. Deze functionaris (interne accountant) kan veelal slechts een rationele functie vervullen bij grote ondernemingen.

De functie sub b. valt in deze situatie uiteraard toe aan de van de bedrijfsleiding onafhankelijke functionaris: de externe accountant.

De binding van de functionele onafhankelijkbeid aan het niet-zijn in dienstbetrekking moet gezien worden tegen de achtergrond van het ontstaan van het beroep.

De ontwikkeling en de organisatie van het beroep is van oorsprong en nog steeds voor het grootste gedeelte gericht op het particuliere bedrijfsleven; in deze sfeer moet de eis van functionele onafhankelijkheid wel samenvallen met die van het niet-zijn in dienstbetrekking, daar men hier geen andere middelen heeft om deze onafhankelijkheid te tonen en te waarborgen.

Stelt men deze eis nu ook aan overheidsaccountants, dan kan er geen andere conclusie getrokken worden dan dat alle overheidsaccountants interne accountants zijn.

De bepalingen in de Ereregelen van het N.I.v.A. en de Voorschriften inzake de beroepsuitoefening van de V.A.G.A. met betrekking tot de overheidsaccountants moeten in deze gedachtengang beschouwd worden als een door de praktijk 
noodzakelijk geworden afwijking van het axioma dat interne accountants geen publieke verklaringen mogen afgeven; enige theoretische fundering is aan deze constructie niet gegeven.

De verklaring hiervan zal misschien gezocht moeten worden in de weinige bekendheid met de situatie op dit gebied bij de overheid.

In dit verband dient gesteld te worden, dat voor de ontwikkeling van het beroep in Nederland niet alleen de verhoudingen in het particuliere beroep bepalend zijn; ook de ontwikkelingen in de overheidssector, waar een toenemend aantal beroepsgenoten werkzaam is, dienen hierbij betrokken te worden. Het vraagstuk van de functionele onafhankelijkheid wordt van een te beperkt uitgangspunt gezien, indien men hierbij alleen de omstandigheden in het particuliere bedrijfsleven in beschouwing neemt.

Het is nog altijd jammer, dat Prof. Limperg indertijd bij zijn uitwerking van bovengenoemde theorie - ter beperking van de stof - de verhouding tot de publiekrechtelijke lichamen onbesproken heeft gelaten.

Bij de overheid - en ook daar alleen - bestaat n.l. de situatie, dat men door wettelijke regelingen onafhankelijkheid van bepaalde functionarissen en/of organen kan creëren (en ook waarborgen), daar waar deze noodzakelijk is.

Een algemeen bekend voorbeeld hiervan is de rechterlijke macht; de functionele onafhankelijkheid der rechters is in de wet vastgelegd; noch een minister noch enig andere overheidsfunctionaris kan op grond van de dienstbetrekking de rechter beïnvloeden; onder omstandigheden wordt de overheid zelf door de rechter veroordeeld. Een actuele figuur in dit verband is ook de „Ombudsman”.

Deze bijzondere situatie, welke nu eenmaal bij de overheid bestaat, maakt het mogelijk ook het vraagstuk van de functionele onafhankelijkheid van de accountant op een andere wijze te benaderen dan in het particuliere bedrijfsleven; dienstbetrekking is hier geen beslissende factor. Daar waar functionele onafhankelijkheid noodzakelijk wordt geacht, wordt deze door de wetgever gecreëerd, ook t.a.v. de controle.

Alvorens deze gevallen nader aan te duiden, is het gewenst, op te merken, dat in het overheidsbeheer zich dezelfde vraagstukken met betrekking tot de controle voordoen als in het particuliere bedrijfsleven.

Ook hier bestaat behoefte aan een controle ten behoeve van de leiding (interne functie) en een controle op de door deze leiding afgelegde verantwoording aan het vertegenwoordigende lichaam (externe functie). Dat men voor de vervulling van laatstgenoemde functie praktisch geen gebruik gemaakt heeft van de particuliere accountant kan men thans slechts als feit constateren.

Teneinde nu te kunnen nagaan in welke gevallen een hiervorenbedoelde, wettelijke regeling van de controle noodzakelijk geacht moet worden (en ook tot stand gebracht is), is het gewenst de verschillende controletaken van de bij de overheid werkzame accountants nader te beschouwen.

Gericht naar het object der controle kan men een onderscheiding maken in accountants, belast met:

a. controle van administraties van derden ten behoeve van de vaststelling van de juiste naleving van overheidsmaatregelen. Deze groep omvat de accountants bij de belastingdienst, de accountants van de prijsregelende organen e.d. 
b. controle van de verslaglegging der resp. nverheidsorganen en de door deze geexploiteerde of (in belangrijke mate) gefinancierde bedrijven of instellıngen.

Tot deze categorie behoren al naar gelang het orgaan, dat de verslaglegging doet, de accountants van de Algemene Rekenkamer. de accountants van de resp. ministeries, de provincie-accountants en de gemeente-accountants.

\section{ad a. Controle van administraties van derden t.a.v. naleving overheidsmaatrege- len}

Bedoeld zijn de belastingwetten, de prijs- en deviezenvoorschriften e.d. De hierbij betrokken accountants komen alleen voor in 's-rijks dienst.

De belastingaccountant is hiervan wel de meest bekende verschijningsvorm; voor de niet-ingewijde is rijksaccountant zelfs synoniem met belastingaccountant.

Historisch is deze verwarrende gelijkstelling te verklaren, doordat de rijksaccountant voor het eerst in de openbaarheid trad (i.c. bekend werd) als belastingaccountant (na de eerste wereldoorlog i.v.m. de oorlogswinstbelasting); ook door hun aantal (zij vormen de grootste groep van de accountants in rijksdienst) en hun directe contacten met het particuliere bedrijfsleven is het begrijpelijk, dat een dergelijke opvatting is ontstaan.

Hoewel hier misschien gevoelsargumenten (traditie) zich tegen zouden verzetten, zou het toch aanbeveling verdienen, teneinde een zuivere onderscheiding mogelijk te maken, de naam ,rijksaccountants" als algemene groepsaanduidıng te gebruiken (accountants werkzaam bij het rijk) en o.m. de belastingaccountants als een speciale groep daarvan te zien.

Aan de omtrent de belastingaccountant in dit blad reeds verschenen beschouwingen ontlenen wij de volgende korte samenvatting.

De functic van de belastingaccountant is de belastinginspectie (in laatste instantie de Minister van Financiën) behulpzaam te zijn bij de vaststelling van die belastingaanslagen, welke een boekhoudkundig onderzoek vereisen. Hiertoe onderzoekt hij in opdracht van deze inspectie de administraties van belastingplichtigen, teneinde de juistheid van de gegevens, nodig voor deze aanslagen, vast te stellen. De uitgebrachte rapporten komen uiteraard niet in de openbaarheid; zij vervullen geen publicke functic doch een functie in de relatie belastingplichtige en belastinginspectie.

De gebruikelijke onderscheiding in interne accountant (orgaan van de bedrijfsleiding) en externe accountant (orgaan van het maatschappelijk verkeer) is voor deze groep mocilijk te hanteren; zij zijn geen externe accountants, die een verslaglegging ten behoeve van het maatschappelijk verkeer certificeren noch interne accountants, die ten behoeve van de bedrijfsleiding de interne verslaglegging controleren.

Vergelijkbaar is hier de bankaccountant, die credietonderzoeken verricht bij de clienten van de bank.

Gezien de speciale doelstelling van het onderzoek, dat uitsluitend plaats vindt ten behoeve van een beheershandeling van een der organen van de Minister en de principiële niet-openbaarheid van de resultaten van dit onderzoek, moet hier m.i. toch van een interne functie gesproken worden.

De rijksaccountants werkzaam bij de prijsregelende organen e.d. treden vooral naar voren in perioden, waarin zich bijzondere economische omstandigheden voordoen (crisisjaren, oorlogs- en na-oorlogstijd). 
De controle op de naleving van de economische overheidsvoorschriften geschiedt in opdracht en ten behoeve van de betrokken ministers.

Naar analogie van hetgeen omtrent de belastingaccountants is opgemerkt, zal ook hier van een interne functie gesproken moeten worden.

\section{ad b. Controle verslaggeving van overheidsorganen e.d.}

Teneinde de onderscheidene functies der hierbij betrokken accountants nader te kunnen aanduiden, is het gewenst de situatie met betrekking tot dit punt bij de resp. overheidsorganen afzonderlijk te behandelen.

\section{Het rijk}

In het staatsapparaat is de controle op het beheer naar twee gezichtspunten te onderscheiden:

- controle op de verslaglegging van de beheerders (i.c. ministers) ten behoeve van de volksvertegenwoordiging;

- controle op de verslaglegging van de door de resp. ministers gedelegeerde beheren ten behoeve van de resp. ministers.

Het beheer is in zijn algemeenheid opgedragen aan de ministers. Teneinde de verantwoordelijkheid voor deze onder hen gestelde, doch gedelegeerde beheren te kunnen aanvaarden is het noodzakelijk, dat zij daarop controle doen uitoefenen.

Een belangrijke plaats neemt hierbij in de controle van de verslagleggingen der beheren door verbijzonderde controle-organen i.c. de accountantsdiensten bij de resp. ministeries. Deze accountantsdiensten controleren dus in opdracht en ten behoeve van de betrokken minister; zij zijn organen van de resp. ministers; zij zijn interne accountants ${ }^{1}$ ). Vergelijking is hier mogelijk met de interne accountant van cen concern, die in opdracht van de hoofdleiding o.m. de filialen en dochterondernemingen controlecrt.

Het zal duidelijk zijn, dat de ministers bij de verantwoording van hun beheer tegenover het vertegenwoordigende lichaam niet kunnen verwijzen naar de verklaringen van de onder hun gezag staande accountantsdiensten; ook hier is het rationeel te achten, dat voor de controle op het beheer van de ministers slechts gebruik gemaakt kan worden van een onafhankelijk van dat beheer staande instantie.

In deze behoefte aan een onafhankelijk controle-orgaan is dan ook door de wet voorzien; de controle van de rijksuitgaven en -ontvangsten is in de grondwet opgedragen aan de Algemene Rekenkamer, waarvan de taak en ook de onafhankelijkheid in de comptabiliteitswet nader is geregeld. Enige belangrijke punten hiervan zijn:

- benoeming op voordracht van de Tweede Kamer der Staten-Generaal;

- ontslag door de Hoge Raad;

- regeling van het salaris bij de wet.

Voor meer uitvoerige beschouwingen over de ontwikkeling van de functie van de Algemene Rekenkamer moge worden verwezen naar het artikel van de heer

1) Volledighcidshalve wordt hier nog gewezen op de enigszins afwijkende positie, die de Centrale Accountantsdienst van het Ministerie van Financiën hierbij inneemt. Dezc dienst vocrt ook controleopdrachten uit ten behoeve van andere ministers. 
L. Götzen „De Algemene Rekenkamer 150 jaar” (M.A.B. juli 1964) en het in 1960 verschenen rapport van de commissie Simons inzake de herziening van de Comptabiliteitswet.

Volledigheidshalve moge hier onder verwijzing naar deze publicaties met betrekking tot de relatie tussen de interne en externe functie nog het volgende opgemerkt worden.

Ter vaststelling van de juistheid van de rekeningen der onderscheidene dienstonderdelen kan de Algemene Rekenkamer gebruik maken van de rapporten der interne accountantsdiensten van de ministeries, zij het dat zij te allen tijde de bevoegdheid heeft zelfstandig een aanvullend of geheel nieuw onderzoek in te stellen (art. 68 lid 1, ontwerp-Comptabiliteitswet). Voorts wordt in het 2e lid van art. 68 bepaald:

„Onze Ministers bevorderen op aanvrage van de Kamer, dat zij, die met de controle belast zijn, hun werkschema's te harer beschikking stellen, en lichten haar volledig in omtrent de controle-bevindingen door overlegging van rapporten en processen-verbaal of op andere door de Kamer aan te geven wijze.”

Resumerende kan dus gesteld worden, dat in het staatsapparaat de Algemene Rekenkamer de externe accountantsfunctie vervult en de accountantsdiensten van de ministeries de interne functie.

\section{De provincies}

$\mathrm{Bij}$ de provincies berust het algemeen bestuur bij provinciale staten (het vertegenwoordigende lichaam); het dagelijks bestuur en het beheer der financiën en eigendommen is opgedragen aan het college van gedeputeerde staten; voor dit bestuur en beheer is het college verantwoording schuldig aan de provinciale staten.

In vele gevallen zijn van het algemene beheer bepaalde activiteiten afgesplitst en gevormd tot bedrijven (afzonderlijke beheerseenheden met een zelfstandige administratie), aan het hoofd waarvan directeuren zijn gesteld, die uiteraard voor hun beheer weer verantwoording schuldig zijn aan het college van gedeputeerde staten.

Met betrekking tot de controle wordt het volgende opgemerkt.

Het zal duidelijk zijn, dat gedeputeerde staten niet de tijd en de deskundigheid hebben om de rekening en verantwoording van het door hen aan de resp. diensthoofden gedelegeerde beheer te controleren.

Teneinde hun verantwoordelijkheid t.d.z. te kunnen dragen, laten zij deze controle beroepsmatig verrichten, hetzij door het aantrekken van een deskundige in ambtelijke dienst, hetzij door inschakeling van een buiten de provinciale organisatie staand accountantskantoor. Deze controle geschiedt dus in opdracht en ten behoeve van gedeputeerde staten; mochten gedeputeerde staten geen behoefte hebben aan controle, dan zijn zij vrij om dit na te laten. Of in een dergelijke situatie van een verantwoord beheer sprake is, kunnen wij hier in het midden laten; duidelijk is, dat met betrekking tot deze controle hier van een interne functie gesproken moet worden.

Gedeputeerde staten leggen op hun beurt de hiervorengenoemde rekeningen van de resp. bedrijven en van de rechtstreeks onder hen ressorterende algemene dienst met de door hen nodig geachte verantwoordingen ter goedkeuring en ter verkrijging van decharge voor aan de provinciale staten.

m a b blz. 149 
Ook de provinciale staten beschikken echter niet over de nodige tijd en deskundigheid om deze rekeningen te controleren.

Ten behoeve van dit orgaan heeft de wet echter wel in de controle voorzien.

Ten aanzien van de zelfstandige dienstonderdelen (i.c. bedrijven en daarmede gelijk te stellen organen) was reeds in 1927 bepaald, dat de rekeningen van deze onderdelen, welke aan de provinciale staten worden aangeboden ter goedkeuring, voorzien moeten zijn van een deugdelijkverklaring (in feite een normale accountantsverklaring) afgegeven door een door provinciale staten aan te wijzen deskundige.

Voor de rekening van de algemene dienst gold $\mathrm{t} / \mathrm{m} 1962$ nog de regeling, dat de Algemene Rekenkamer deze rekening deugdelijk moest verklaren alvorens de provinciale staten deze konden vaststellen.

In de Provinciewet 1962 is deze constructie verlaten; thans moet ook de rekening van de algemene dienst vergezeld gaan van een verslag van het onderzoek naar de deugdelijkheid der rekening, in te stellen door een door provinciale staten aan te wijzen deskundige.

(In het voetspoor van de wijziging van de gemeentewet in 1950 is in de nieuwe Provinciewet de hiervoren genoemde deugdelijkverklaring vervangen door een verslag van het onderzoek naar de deugdelijkheid; een verslag biedt gelegenheid naast het oordeel nog nadere beschouwingen en toelichtingen te geven.)

Resumerend kan gesteld worden, dat bij de provincies twee controlefuncties vervuld moeten worden; een interne functie ten behoeve van de algemene leiding i.c. gedeputeerde staten en een externe functie ten behoeve van het dechargerende orgaan i.c. de provinciale staten.

De verslagen van het onderzoek ten behoeve van de provinciale staten zijn openbare stukken (zij worden met de resp. rekeningen en verantwoordingen in het openbaar behandeld); de publieke functie van de accountant komt hiermede duidelijk naar voren.

Het behoeft voor onze lezers geen betoog, dat indien beide functies door één functionaris (dienst, kantoor) vervuld worden (evenals in het particuliere beroep het normale geval) bij de taakuitoefening laatstgenoemde functie prevaleert.

De omstandigheid, dat volgens de wet de aanwijzing moet geschieden door provinciale staten, die hierin geheel vrij zijn, betekent dat de onafhankelijkheid t.o.v. het beherende college (i.c. gedeputeerde staten) duidelijk gemarkeerd is.

(Hoewel ten overvloede voor vakgenoten, wordt nog opgemerkt dat de accountant een oordeel uitspreekt over de juistheid van de verslaglegging van het gevoerde bebeer door gedeputeerde staten; een oordeel over het beleid als zodanig is voorbehouden aan het politieke orgaan i.c. provinciale staten. In het kader van dit artikel is het niet mogelijk nader in te gaan op de zich hierbij voordoende problemen; verwezen moge worden o.m. naar de parlementaire behandeling van de wijziging van de gemeentewet in 1950 en naar die van de provinciewet in 1962, het artikel van de heer J. H. Textor in M.A.B. 1952 „De verhouding tussen beleid en controle als functies van het bestuur der overheid" en van ondergetekende in Financieel Overheidsbeheer 1962 „De functie en de taak van de provincie-accountant”.)

Tot slot zij er nog op gewezen, dat er ook een onafhankelijkheid moet bestaan t.o.v. de provinciale staten, daar de goedkeuring van de Kroon van het besluit 
dezer staten tot vaststelling van de rekeningen in de practijk steunt op de verklaring van de accountant.

In dit verband wordt nog het volgende opgemerkt.

Hoewel de overheidsfunctionaris in het algemeen reeds een met vele waarborgen omringde rechtspositie heeft, zou het aanbeveling verdienen de onafhankelijkheid van de hier bedoelde functionarissen nog verder te accentueren door in de regeling van het ontslag en de vaststelling van de salarissen op analoge wijze te voorzien als bij de Algemene Rekenkamer.

Deze in de practijk van de huidige verhoudingen misschien wat „zwaar” lijkende aanvulling zou vermoedelijk eenvoudiger te regelen zijn bij de eventuele ontwikkeling van een gemeenschappelijk controle-orgaan ten behoeve van de gezamenlijke provincies.

\section{De gemeenten}

$\mathrm{Bij}$ de gemeenten bestaat een soortgelijke situatie als bij de provincies. Ook hier vervult de gemeente-accountant een interne functie als controleur t.b.v. burgemeester en wethouders van de verslagleggingen der door dezen gedelegeerde beheren (i.c. diensten en bedrijven) en een externe functie als controleur t.b.v. de raad van de verslaglegging door burgemeester en wethouders.

Evenals bij de provincies is deze materie in de wet (i.c. de gemeentewet) geregeld, hetgeen inhoudt, dat de raad de deskundige aanwijst, die t.b.v. hem een onderzoek instelt naar de juistheid van de rekeningen en verantwoordingen, welke burgemeester en wethouders aan de raad ter goedkeuring voorleggen.

Opgemerkt moet hierbij worden, dat in ongeveer 900 van de bijna 1000 gemeenten de controle wordt uitgeoefend door een door de Vereniging van Nederlandse Gemeenten in het leven geroepen accountantsdienst. De hier werkzame accountants zijn aangesteld door de Vereniging, ten opzichte van de individuele gecontroleerde gemeente bestaat geen enkel dienstverband.

Gezien deze situatie kan gesteld worden, dat met betrekking tot de onafhankelijkheid van de functie hier feitelijk weinig vraagpunten overblijven.

Voor de grote gemeenten, welke veelal over een eigen dienst beschikken, zou, teneinde ook hier de onafhankelijkheid wat duidelijker te accentueren, een soortgelijke regeling als hiervoren bij de provincie-accountant is bepleit, aanbeveling verdienen.

\section{Slotbeschouwing}

Een interessante vraag is nog of de in het voorgaande beschreven externe overheidsaccountant, die publieke verklaringen afgeeft, ook beschouwd moet worden als een vertrouwensman van het maatschappelijk verkeer.

De critische punten waaraan het begrip vertrouwensman van het maatschappelijk verkeer getoetst dient te worden zijn:

a. deskundigheid, hetgeen betekent, dat hogere eisen gesteld kunnen worden dan aan niet-beroepsmatige controle-organen;

b. onafhankelijkheid, welke gezien moet worden als een functionele onafhankelijkheid van de beheersorganen.

Met betrekking tot de deskundigheid bestaan hier, gezien het aantal leden van erkende accountantsverenigingen dat in deze sector werkzaam is, in het algemeen 
geen problemen; verwacht kan worden, dat t.z.t. uitsluitend registeraccountants voor deze functies in aanmerking zullen komen.

Zijn onafhankelijkheid is, zoals hierboven reeds is uiteengezet, door wettelijke waarborgen omringd, zij het dat een formele afronding daarvan voor provincieen gemeente-accountant nog aanbeveling verdient.

De externe overheidsaccountant is echter geen „openbare” accountant in die zin, dat een ieder hem kan vragen een opdracht uit te voeren; zijn opdracht is in de wet vastgelegd.

Een andere vraag is of hier sprake is van maatschappelijk verkeer.

Hoewel in eerste aanleg dit maatschappelijk verkeer gezien werd als het financieel-economisch verkeer tussen het bedrijfsleven en de vermogensmarkt, heeft men hieraan later een wijdere strekking gegeven en rekent men hiertoe allen, die op enigerlei wijze bij de onderneming zijn betrokken of geïnteresseerd (dus niet alleen huidige en toekomstige geldgevers, doch ook crediteuren, werknemers enz.).

Uitgaande van bovenstaande definiëring van het maatschappelijk verkeer bestaat er geen enkel bezwaar hiertoe ook te rekenen de verhouding tussen de overheid als beheerster t.b.v. de gemeenschap en de contribuabelen, die de middelen voor dat beheer bijeen brengen.

De conclusie zal derhalve moeten luiden, dat de functie van vertrouwensman van het maatschappelijk verkeer zo ruim gezien moet worden, dat daar ook onder valt de externe overheidsaccountant. 